\title{
Estudo da aplicação da cinza de caldeira a coque nas camadas de base e sub-base de pavimentos
}

\author{
Virlene Leite Silveira ${ }^{1}$, Antonio Carlos Rodrigues Guimarães ${ }^{2}$, Carmen Dias Castro ${ }^{3}$ \\ ${ }_{1}^{1}$ nstituto Militar de Engenharia, Brasil, virlene_cea@hotmail.com \\ 2Instituto Militar de Engenharia, Brasil, cap-guimaraes@hotmail.com \\ 3Instituto Militar de Engenharia, Brasil, carmendc14@gmail.com
}

\section{Recebido:}

21 de maio de 2018

Aceito para publicação:

6 de maio 2019

Publicado:

31 de agosto de 2019

Editor de área:

Kamilla Vasconcelos

\section{Palavras-chaves:}

Cinza de caldeira a coque;

Pavimentação;

Estabilização de solos;

Reações pozolânicas.

\section{Keywords:}

Coke boiler ash;

Paving;

Soil stabilization;

Pozzolanic reactions.

DOI:10.14295/transportes.v27i2.1690

\begin{abstract}
RESUMO
Este estudo apresenta a caracterização de cinzas obtidas do processo de beneficiamento do níquel em usina siderúrgica, tendo como objetivo principal, avaliar sua aplicabilidade para estabilização de solos em camadas de base e sub-base de pavimentos rodoviários, através da mistura destas a um solo regional e cal. Foram realizados ensaios de caracterização química, física e mecânica, para o solo puro e para o mesmo solo com a adição de diferentes teores de cinzas e cal em diferentes tempos de cura a fim de se verificar a ocorrência de reações pozolânicas, tais que resultassem em aumento da rigidez do solo. A análise mecânica constituiu de ensaio de módulo de resiliência em corpos de prova contendo $10 \%, 15 \%$ e $20 \%$ de cinza em substituição a massa seca do solo e $8 \%, 13 \%$ e $18 \%$ de cinza e $2 \%$ de cal em substituição a massa seca da cinza. Como resultados, encontrou-se que a cinza de caldeira a coque provoca acréscimo da rigidez das misturas com aumento do tempo de cura, podendo ter seu efeito potencializado pela ação da cal, efeito observado através dos ensaios triaxial de cargas repetidas. Os resultados obtidos para todos os teores de cinza foram satisfatórios, ressaltando o emprego positivo do material para aplicação em camadas de pavimentos em vias de baixo a médio tráfego.
\end{abstract}

\section{ABSTRACT}

This study presents the characterization of ash obtained of the beneficiation process of nickel in steel plant having as main objective, to evaluate its applicability for stabilization of soils in base and sub-base layers of road pavements, through the mixture of these to a regional soil and lime. Chemical, physical and mechanical characterization tests were carried out for the pure soil and for the same soil with the addition of different levels of ash and limes in diferente healing times in order to verify the occurrence of pozzolanic reactions, such that result in increased mechanical resistance and soil rigidity. The mechanical analysis consisted of a resilient modulus test in test specimens containing $10 \%$, $15 \%$ and $20 \%$ of ash replacing the dry weight of the soil and $8 \%, 13 \%$ and $18 \%$ of ash and $2 \%$ of lime in replacement of the dry weight of $t$ ash. As results, it was found that the ashes of the coke boiler causes increased rigidity of the mixtures with increased healing time, and may have its effect potentiated by the action of lime, effect observed through the triaxial testing of repeated loads. The results obtained for all levels of ash were satisfactory, emphasizing the positive employment of the material for application in layers of pavements.

\section{INTRODUÇÃO}

Um dos grandes malefícios do mundo moderno é a grande geração de resíduos e o seu inadequado descarte. Nas últimas décadas uma maior preocupação com a preservação ambiental tem levado o governo e a sociedade a impor medidas no sentido de compatibilizar o crescimento industrial e tecnológico com o meio ambiente. Nestas circunstâncias, além da criação de legislações mais rigorosas e maior fiscalização, do surgimento de organizações em prol do meio am- 
biente, inclui-se também como uma alternativa economicamente viável e sustentável, o aproveitamento do rejeito de uma indústria como insumo para outra.

A cinza de caldeira a coque, também tratada como cinza leve ou volante pela sua granulometria, é oriunda do processo de geração de vapor em caldeira por uma indústria siderúrgica de beneficiamento de níquel no Estado de Goiás, onde são geradas cerca de 45 mil toneladas por ano. A reutilização de diversos tipos de cinzas já desperta grande interesse em alguns ramos da indústria e diversas pesquisas direcionadas ao seu aproveitamento tornaram possível seu emprego em obras de engenharia, principalmente na construção civil.

Sabe-se que a maioria das obras em engenharia é sustentada por solo, e este muitas vezes não apresenta os requisitos necessários para tal. Os solos em seu estado natural podem não apresentar resistência para suportar os carregamentos impostos, porém esta propriedade pode ser melhorada com adição de um agente cimentante como a cal e o cimento Portland, que já são consagrados na construção civil, bem como os diversos tipos de cinza que vêm despontando interesse no meio acadêmico por suas propriedades e apresentando resultados satisfatórios, devido à sua ação pozolânica.

0 uso de cinzas em engenharia data desde o tempo dos Romanos, mas foi em meados dos anos 30 que passaram a ter maior importância, quando estas começaram a estar disponíveis em quantidades significativas, ocupando um grande espaço em indústrias e demandando de infraestrutura especializada em restrição às legislações ambientais (LEANDRO e FABBRI, 2001; NETTO, 2006).

Na pavimentação, as cinzas começaram a ser utilizadas por volta da década de 50 , havendo registros que apontam uma das primeiras aplicações de cinza em camadas de base foi em um trecho construído em 1957 perto de Colfax, Iowa, EUA, sendo monitorada e após 4 anos se manteve em boas condições. Outro caso de sucesso foi o uso das cinzas na estrada de Gorgas para Parrish, no Alabama, EUA, onde também ocorreu a estabilização da camada de base usando cinzas e mesmo sendo submetida a alto tráfego, devido as proximidades de uma área de mineração, esta se permaneceu em boas condições (HOOVER et al., 1962; HESTER, 1967).

Assim como em outras regiões do mundo, no Brasil o uso das cinzas na construção civil já tem apresentado avanços significativos principalmente se tratando de pavimentação. Pesquisas realizadas desde a década de 70, conduzidas no Brasil, primeiramente por PINTO (1971), NARDI (1975) e MARCON (1977) apresentaram avanços significativos e boas perspectivas no emprego de cinzas em pavimentação na estabilização de solos.

De forma a se alinhar às estratégias de sustentabilidade quanto à geração e disposição de resíduos, este estudo busca auxiliar na minimização dos efeitos de geração e descarte, contribuir para o estudo de um novo material em obras de pavimentação e preservação dos recursos naturais. Tendo como objetivo principal investigar a possibilidade da utilização da cinza de caldeira a coque em misturas com solo, através de experiências dispostas na literatura e de ensaios laboratoriais, visando sua aplicação na construção de bases e sub-bases de pavimento.

\subsection{Cinzas volantes e sua aplicação em pavimentação no Brasil e no mundo}

A cinza volante se enquadra segundo a ABNT NBR 12653 (1992) e ASTM C618 (2003) entre os materiais denominados pozolânicos. Onde a ABNT NBR 12653 (1992) fixa as condições exigíveis para materiais pozolânicos para uso como adição onde são desejadas ações aglomerantes e a norma da American Society for Testing Materials (ASTM) através da ASTM C618 (2003), 
classifica as cinzas volantes de acordo com sua composição para sua utilização em concreto ou cimento, onde sua ação pozolânica também é desejada.

A ABNT NBR 12653 (1992) define os materiais pozolânicos da seguinte maneira: "Materiais silicosos ou silicoaluminosos que, por si sós, possuem pouca ou nenhuma atividade aglomerante, mas que, quando finamente divididos e na presença da água, reagem com o hidróxido de cálcio à temperatura ambiente, para formar compostos com propriedades aglomerantes". SILVA (2011) afirma que a principal propriedade de uma pozolana é a sua capacidade de reagir e se combinar com o hidróxido de cálcio, formando compostos estáveis de poder aglomerante, tais como silicatos e aluminatos de cálcio hidratados.

A cinza leve ou cinza volante (fly ash) representa um material de granulometria fina (100\% menor que $0,15 \mathrm{~mm}$ ), não plástico e com propriedades pozolânicas, resultantes da combustão do carvão pulverizado ou moído, que são arrastadas pelos gases de combustão e coletadas através do fluxo de gases provenientes da combustão de carvão nas caldeiras pelos equipamentos de retenção de material particulado (NARDI, 1975; LEANDRO, 2005).

De acordo com AHMARUZZAMAN (2010) e LEANDRO (2005), esse tipo de cinza se apresenta geralmente na cor cinza, abrasiva, principalmente alcalina e refratária na natureza e são materiais que se encontram na categoria de materiais pozolânicos e/ou cimentícios. Para ROHDE et al. (2006) e SIQUEIRA (2010), os principais constituintes das cinzas são os cristais de sílica $\mathrm{SiO}_{2}$, alumina $\mathrm{Al}_{2} \mathrm{O}_{3}$, óxido de ferro $\mathrm{Fe}_{2} \mathrm{O}_{3}$, cal CaO, além de outros componentes em menores quantidades menores como $\mathrm{MgO}, \mathrm{Na}_{2} \mathrm{O}, \mathrm{K}_{2} \mathrm{O}, \mathrm{SO}_{3}, \mathrm{MnO}$ e $\mathrm{TiO}_{2}$, bem como partículas de carbono não consumidas durante a combustão

Quanto à utilização desse material, LEANDRO (2005) afirma que o seu uso mais comum no Brasil é na fabricação de cimentos Portland pozolânicos e na confecção de concretos, porém, a cinza volante, por ser um material finamente dividido e apresentar boa atividade pozolânica, é empregada em vários ramos da construção civil em todo mundo, como em construção de barragens e aterros rodoviários, estabilização de solos, fabricação de tijolos, telhas, artefatos de cimento (blocos estruturais, blocos de vedação e blocos para pavimentação), como em aditivo em concretos, além de também poder ser utilizada como fertilizante. CHERIAF et al. (1999) apud MARGON (2002), explicam que a utilização potencial da cinza volante é principalmente controlada pela sua composição química, embora a pequena granulometria das partículas também seja uma importante consideração.

Mais especificamente, BIN-SHAFIQUE (2005) afirma que as cinzas volantes possuem características de cimentação que permitem sua utilização para a estabilização de solos, sem utilização de ativadores para melhorar suas propriedades mecânicas, como em solos moles para aplicação em bases e sub-bases, contribuindo para se ter uma plataforma de trabalho estável favorável para construção de rodovias. As cinzas volantes são capazes de desenvolver reações pozolânicas e possuem características para estabilização de solos, pois apresentam em sua composição os principais elementos responsáveis pela atividade pozolânica como $\mathrm{Si}_{2} \mathrm{O}, \mathrm{Al}_{2} \mathrm{O}_{3}, \mathrm{Fe}_{2} \mathrm{O}$, $\mathrm{CaO}, \mathrm{MgO}, \mathrm{SO}_{3}, \mathrm{Na}_{2} \mathrm{O}$ e $\mathrm{K}_{2} \mathrm{O}$ (ROHDE et al., 2006).

Quanto sua utilização, SUNDSTRON (2012), relata uma serie de barreiras para a utilização das cinzas como matéria-prima. Entre as principais destaca-se primeiramente a inexistência de um diálogo entre o setor carbonífero, mineradoras de carvão, siderúrgicas e metalúrgicas, usinas termoelétricas e demais indústrias com as entidades de pesquisa e órgão de controle ambiental, gerando falta de políticas, legislação e subsídios favoráveis que venham a incentivar o 
consumo desses resíduos, com potencial consumo das cinzas. Além do fato de que muitas empresas não estão interessadas e nem preparadas para investir neste campo de estudo, classificando a cinza simplesmente como um resíduo descartável.

Mesmo assim, nas últimas décadas, estudos vêm sendo desenvolvidos no Brasil, demonstrando grande potencialidade do uso de cinzas em pavimentação (PINTO, 1971; NARDI, 1975; MARCON, 1977; LEANDRO, 2005; VIZCARRA, 2010; LOPES, 2012; entre outros), tanto em estruturas rígidas como flexíveis de pavimentos. Segundo SILVA et al. (1999) no que se refere à pavimentação, é enorme a potencialidade de uso de cinzas e que apesar da potencialidade, são materiais raramente empregados no Brasil, em obras viárias.

0 primeiro registro de estudo da utilização de cinzas na pavimentação no Brasil foi feito por PINTO (1971). O autor verificou o comportamento de uma cinza volante produzida em uma termoelétrica localizada ao sul do país, como agente estabilizador de uma areia. Pouco depois, foram desenvolvidos outros dois trabalhos importantes e de grande referência para o estudo das cinzas em camadas de pavimentos. NARDI (1975) e MARCON (1977) através de seus estudos comprovaram a viabilidade da estabilização de areia com cinza volante e cal.

Estes primeiros estudos resultaram na implantação de um trecho experimental localizado às margens da BR-101, no município de Imbituba/SC, onde, sobre o subleito de areia, foi construída uma sub-base de areia estabilizada com cal e cinza volante e segundo FARIAS (2005), neste trecho foram instaladas seções de instrumentação e os resultados monitorados foram bastante satisfatórios, aprovando o desempenho do material.

Em termos práticos a Fundação de Ciência e Tecnologia - CIENTEC, que pesquisou misturas de solos com cal e cinza volante para aplicação em pavimentação, tendo como base o projeto CICASOL - Pavimentos de Solos Estabilizados com Cinza Volante e Cal (1982), onde foram empregadas algumas dessas misturas em posteriormente fiscalizadas pelo CIENTEC e citadas no trabalho de MALLMANN (1996):

- $14 \mathrm{~km}$ de pavimento utilizando como base cinza volante, cal e areia, no terminal de Santa

Clara (COPESUL) e ruas de infraestrutura da Petroflex, ambas localizadas no município de Triunfo (RS);

- Revestimento de quatro bacias de decantação para receber efluentes líquidos da Usina de Candiota;

- Execução de base do arruamento da Usina de Candiota;

- Entre outras experiências práticas conhecidas, tem-se um trecho experimental de $1000 \mathrm{~m}$ com base de cinza volante, areia e cal na BR 101 - Imbituba SC (SILVA e CHIES, 1997);

- Obras de infraestrutura e urbanização nas áreas periféricas dos municípios de Charqueadas e São Jerônimo, no Rio Grande do Sul (FARIAS, 2005).

Em geral, tanto a experiência nacional quanto internacional, apontam para um bom desempenho da cinza volante como material de pavimentação, em especial como estabilizante de solos.

\section{PROGRAMA EXPERIMENTAL}

Neste estudo trabalhou-se com três materiais diferentes: Solo, Cinza de caldeira a coque e a Cal, bem como as misturas decorrentes destes materiais com diferentes teores de cinza. 


\subsection{Materiais}

A cinza empregada no estudo, denominada cinza de caldeira a coque, foi coletada em uma Empresa de beneficiamento de Níquel, localizada na zona rural do município de Niquelândia, no estado de Goiás, onde são geradas cerca de 45 mil toneladas por ano (FIG.1a).

A cinza de caldeira a coque é obtida a partir da calcinação a uma temperatura entre $800^{\circ} \mathrm{C}$ $900^{\circ} \mathrm{C}$ de uma mistura de $68 \%$ de coque, $30 \%$ de calcário e $2 \%$ de areia. Nesse processo são obtidos dois materiais distintos que são separados em função da diferença de suas densidades: a cinza leve e a cinza pesada. A cinza pesada sedimenta-se no leito da caldeira, onde posteriormente é retirada por uma rosca transportadora e resfriada. A cinza de caldeira a coque, é arrastada e resfriada por uma corrente de ar juntamente com os gases residuais oriundos da queima.

O solo estudado foi retirado de uma jazida localizada na zona rural do município de Niquelândia - GO (FIG.1b). A escolha de tal jazida deve-se à proximidade da Siderúrgica geradora das cinzas, para que a aplicação das cinzas em pavimentos seja também viável economicamente.

A cal utilizada nas misturas foi a denominada Cal hidratada calcítica, do tipo CHIII, conhecida com Minas Cal.

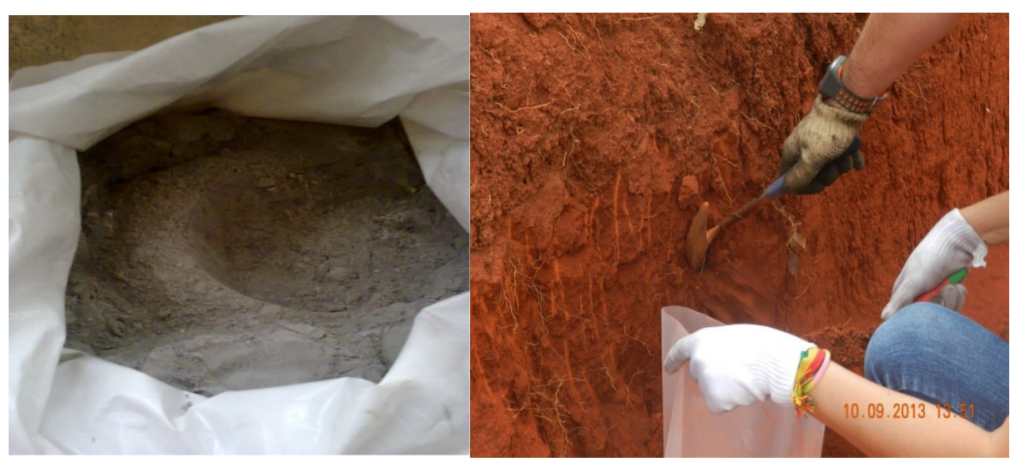

(a)

(b)

Figura 1. Aspecto da cinza de caldeira a coque (a) e Aspecto da jazida do solo estudado (b)

\subsection{Métodos}

Os ensaios realizados para avaliação do comportamento da cinza de caldeira a coque na pavimentação constituíram duas etapas. A primeira etapa, baseou-se na caracterização dos materiais estudados, conforme mostrado na TAB.1, e na determinação do teor ótimo da mistura solocinza e solo-cinza-cal.

Tabela 1: Relação dos ensaios realizados com a cinza volante e o solo

\begin{tabular}{|c|c|c|c|}
\hline Solo & Físicos & $\begin{array}{l}\text { Granulometria } \\
\text { Densidade Real dos grãos } \\
\text { MCT } \\
\text { Limites de Atterberg } \\
\end{array}$ & $\begin{array}{l}\text { DNER-ME 083/98 } \\
\text { DNER-ME 084/95 } \\
\text { DNER-ME 258/94, DNER-ME 256/94 } \\
\text { DNER-ME 122/94, DNER-ME 082/94 }\end{array}$ \\
\hline \multirow{2}{*}{$\begin{array}{l}\text { Cinza de caldeira a } \\
\text { coque }\end{array}$} & Físicos & $\begin{array}{l}\text { Granulometria } \\
\text { Densidade Real dos grãos }\end{array}$ & $\begin{array}{l}\text { DNER-ME 083/98 } \\
\text { DNER-ME 084/95 }\end{array}$ \\
\hline & Químicos & $\begin{array}{l}\text { MEV e EDS } \\
\text { Lixiviação e solubilização }\end{array}$ & $\begin{array}{l}-\overline{-} \\
\text { ABNT NBR 10005/2004 e ABNT NBR 10005/2004 }\end{array}$ \\
\hline
\end{tabular}


Nesta pesquisa foram estudadas misturas de solo e cinza, e misturas de solo, cinza e cal. Os teores de cinza a serem adicionados a mistura foram baseados na literatura disponível sobre o tema. Com base em FARIAS (2005), LEANDRO (2005), LOPES (2011), VIZCARRA (2010) definiu-se os teores usados nesta pesquisa como $10 \%, 15 \%$ e $20 \%$ de cinza de caldeira a coque em substituição a massa seca de solo. Enquanto os teores da cal foram baseados no método das pastilhas (NOGAMI e VILLIBOR, 1995).

Este método é geralmente usado para classificação de solos e baseia-se em avaliações de pastilhas moldadas com o solo em anéis de inox. Moldam-se os anéis com a amostra de solo, estas são secas em estufa e faz-se a medida da contração diametral e em seguida, as pastilhas são submetidas à reabsorção de água e faz-se a medida da expansão e da penetração utilizando uma agulha padrão. A análise dos parâmetros permite fazer o enquadramento do solo quanto ao grupo MCT pertencente.

0 resultado para o melhor teor de cal a ser utilizado é aquele em que a mistura tem uma melhora significativa nos índices medidos: contração e penetração. Os criadores da metodologia sugeriram que a escolha do teor se dê de acordo com a mudança de comportamento do material, seguindo as classificações propostas pelo método de um solo não laterítico para laterítico. Devido a presença da cinza, que já apresenta características pozolanicas, o teor da cal usado neste estudo foi de $2 \%$, acima disto o comportamento do material não apresentou mudanças significativas (SILVEIRA, 2015).

Ou seja, pesquisou-se tanto o efeito da adição da cinza, quanto o efeito da adição desta cinza com cal, ambos incorporados a um solo local. Baseando-se nos teores de $10 \%, 15 \%$ e $20 \%$ de cinza conforme literatura e 2\% de cal definido pelo MCT expedito, foram preparados 14 corpos de prova com teores diferentes, estes que são apresentados na TAB.2 que descreve os materiais

Sendo assim, foram estudadas misturas de $10 \%, 15 \%$ e $20 \%$ de cinza em substituição ao solo seco e de $2 \%$ da cal, conforme estabelecido pelo método das pastilhas, foi feita em substituição a massa seca das cinzas. No total foram preparados 14 corpos de prova, sendo 2 CP's para cada teor estudado. As misturas estudadas, seus respectivos teores de cada material e sua sigla representativa são mostrados na TAB.2:

Tabela 2: Composição e Teores das Misturas estudadas nesta pesquisa

\begin{tabular}{|c|c|c|c|c|}
\hline Material/Mistura & Solo (\%) & Cinza de caldeira a coque (\%) & Cal (\%) & Símbolo \\
\hline 1 -Solo Puro & 100 & - & - & SP-1 \\
\hline 2 - Solo Puro & 100 & - & - & SP-2 \\
\hline 4 - Mistura solo-cinza & 90 & 10 & - & S90/CV10 - 1 \\
\hline 5 - Mistura solo-cinza & 90 & 10 & - & $\mathrm{S} 90 / \mathrm{CV} 10-2$ \\
\hline 6 - Mistura solo-cinza & 85 & 15 & - & S85/CV15-1 \\
\hline 7 - Mistura solo-cinza & 85 & 15 & - & $\mathrm{S} 85 / \mathrm{CV} 15-2$ \\
\hline 8 - Mistura solo-cinza & 80 & 20 & - & $\mathrm{S} 80 / \mathrm{CV} 20-1$ \\
\hline 9 - Mistura solo-cinza & 80 & 20 & - & $\mathrm{S} 80 / \mathrm{CV} 20-1$ \\
\hline 10 - Mistura solo-cinza-cal & 90 & 08 & 02 & s90/CV08/C02-1 \\
\hline 11 - Mistura solo-cinza-cal & 90 & 08 & 02 & $\mathrm{~S} 90 / \mathrm{CV} 08 / \mathrm{CO} 2-2$ \\
\hline 12 - Mistura solo-cinza-cal & 85 & 13 & 02 & $\mathrm{~S} 85 / \mathrm{CV} 13 / \mathrm{CO} 2-1$ \\
\hline 13 - Mistura solo-cinza-cal & 85 & 13 & 02 & $\mathrm{~S} 85 / \mathrm{CV} 13 / \mathrm{CO} 2-2$ \\
\hline 14 - Mistura solo-cinza-cal & 80 & 18 & 02 & $\mathrm{~S} 80 / \mathrm{CV} 13 / \mathrm{CO} 2-1$ \\
\hline 15 - Mistura solo-cinza-cal & 80 & 18 & 02 & $\mathrm{~S} 80 / \mathrm{CV} 13 / \mathrm{CO} 2-2$ \\
\hline
\end{tabular}

Os ensaios de cargas repetidas constituíram a segunda fase deste trabalho. Fase esta, onde foram realizados os ensaios de Módulo de Resiliência (DNIT 181/2018), com intuito de investigar eventual ganho de rigidez no solo a partir da adição da cinza e da cal em diversos tempos 
de cura. Para isso foi ensaiado o solo puro, o solo em misturas com cinza e em misturas com a cinza e a cal, todos realizados na umidade ótima e energia intermediária. Ressalta-se que, para cada CP de uma dada mistura, foi feita uma réplica, de modo a se fazer uma análise mais criteriosa.

Nas misturas solo-cinza nos teores de $10 \%$ e $15 \%$ de cinza, e no solo puro, foram realizados ensaios em 4 períodos após a confecção do corpo de prova: 12h, 7 dias, 20 dias e 70 dias, buscando-se pesquisar o efeito da cura. As misturas contendo $20 \%$ de cinza e todas as outras contendo a cal foram ensaiadas imediatamente após a confecção do corpo de prova e mais dois períodos: 12 dias e 70 dias.

As FIG. 2 mostram o material imediatamente antes da homogeneização da mistura e o corpo de prova sendo extraído, pronto para realização do ensaio de MR.

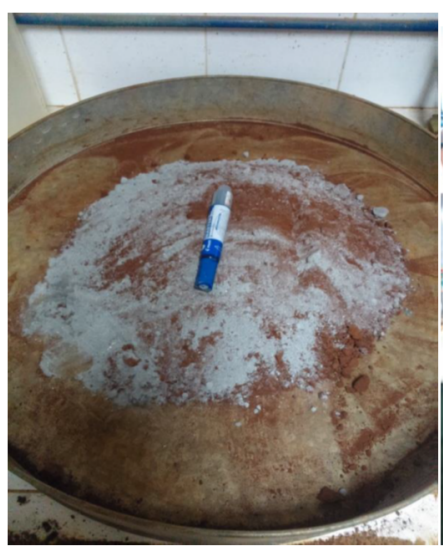

(a)

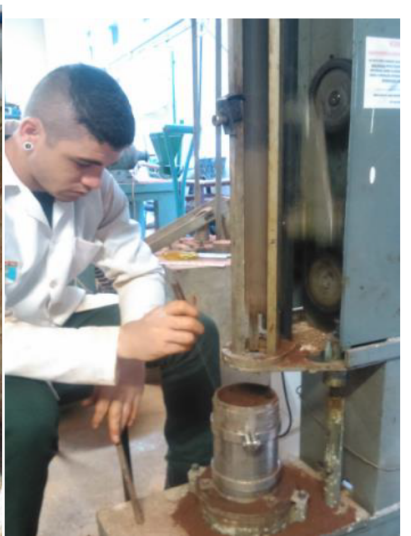

(b)

Figura 2. Mistura solo-cinza sendo preparada para o ensaio de compactação (a) e extração do corpo de prova após compactação (b).

\section{RESULTADOS}

Inicialmente foi realizada a análise granulométrica para reconhecimento dos tamanhos dos grãos das partículas do solo local (FIG. 3).

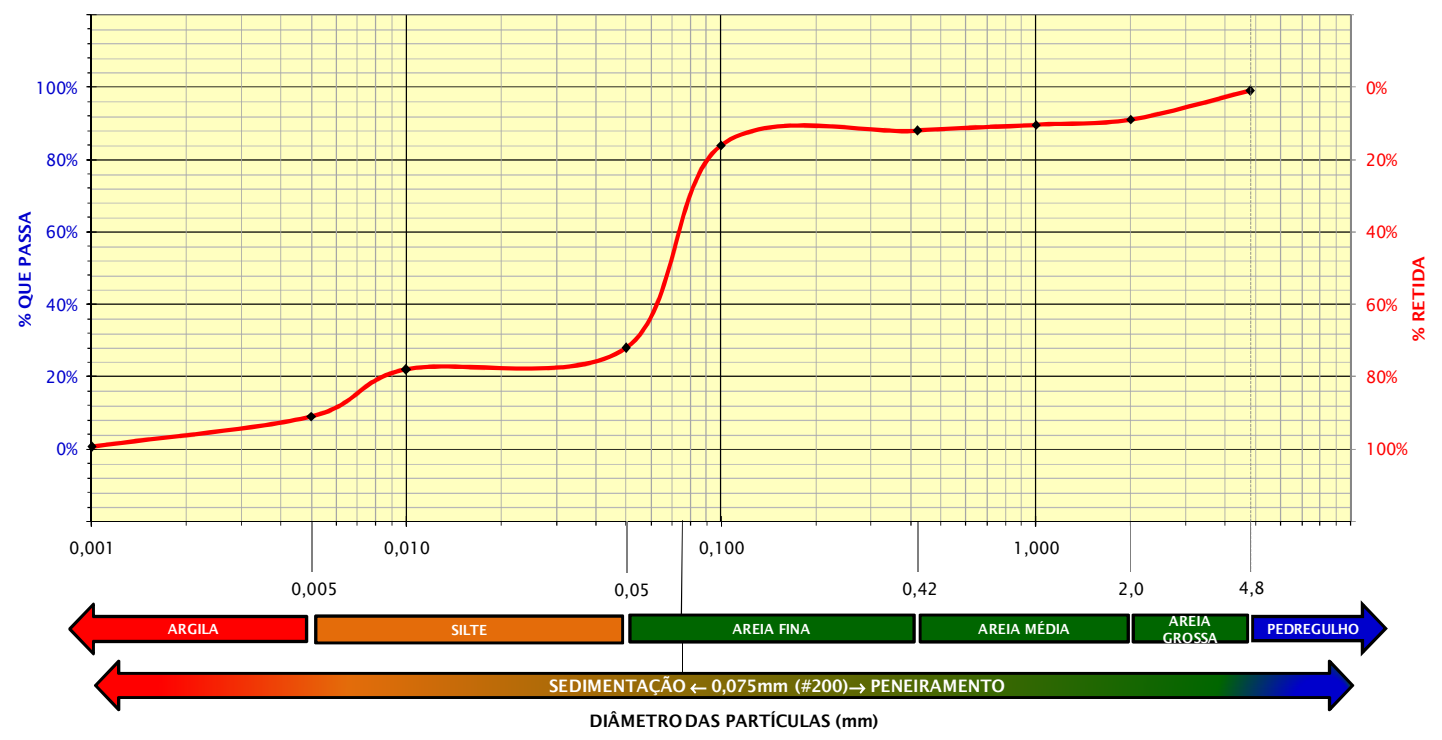

Figura 3: Gráfico do ensaio de granulometria por peneiramento e sedimentação do solo 
O ensaio de granulometria evidenciou alta presença de finos, em torno dos $90 \%$ do material passante na peneira de no 10 e cerca de $78 \%$ passante na peneira $\mathrm{n}$ o 200 .

Para os Limites de Atterberg, os resultados foram: 37,9\% para Limite de liquidez, 18,4\% para limite de plasticidade, consequentemente $19,5 \%$ o valor do índice de plasticidade. Associando a granulomentria aos valores de Limites, temos a classificação do solo de acordo com o SUCS, onde este se integra no grupo "CL", ou seja, uma argila de baixa compressibilidade e a classificação HRB, onde o solo se enquadra no grupo A6 da classificação, representado por solos finos.

Se tratando do território nacional, a classificação geotécnica MCT desenvolvida especificamente para fins rodoviários, enfoca adequadamente as características e peculiaridades dos solos apresentados em ambientes tropicais. Esta classificação apontou para um solo LG', ou seja, laterítico argiloso, solo característico por menores capacidade de suporte e módulo de resiliência, porém mais resistentes à erosão hidráulica quando compactados apropriadamente

Partindo para a caracterização da cinza, sua granulometria é mostrada na FIG. 4.

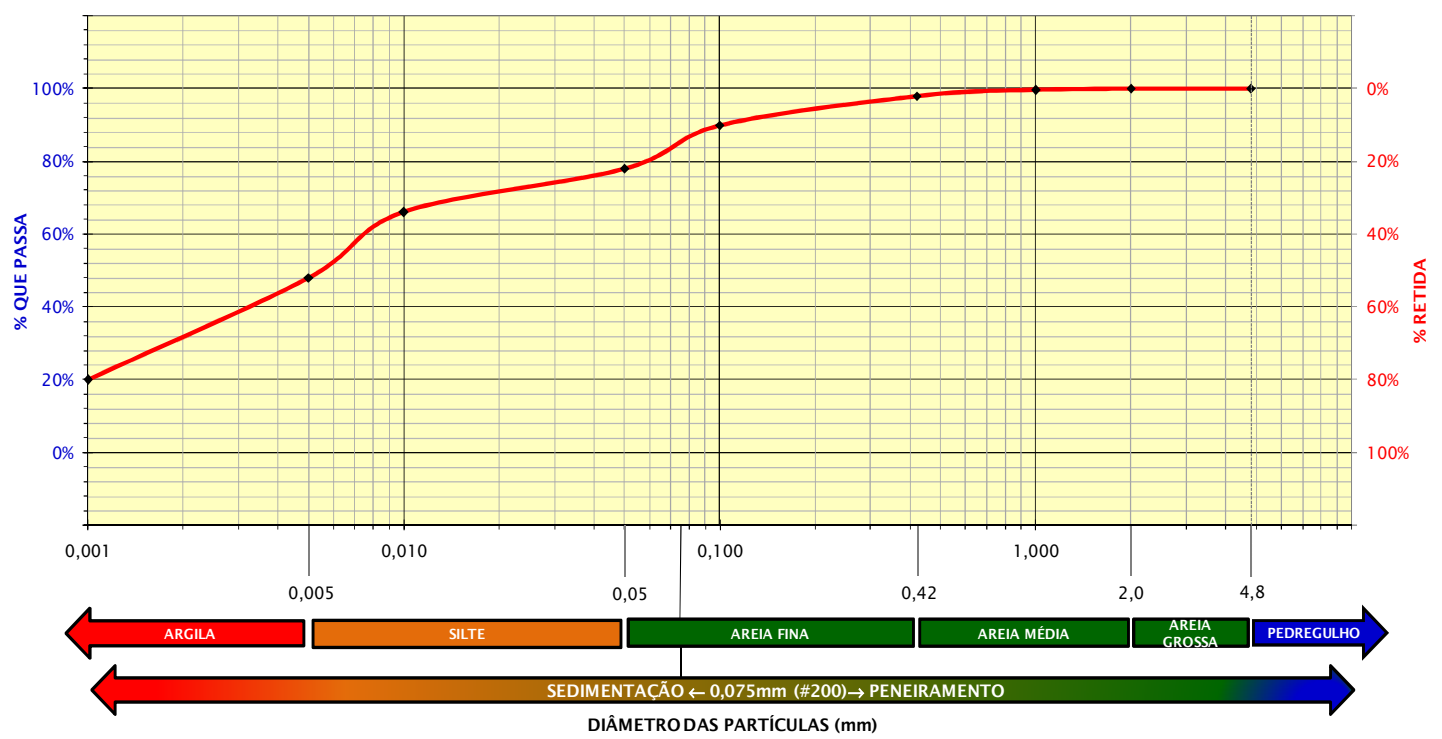

Figura 4: Gráfico do ensaio de granulometria por peneiramento e sedimentação da cinza

O gráfico representado pela FIG. 3 permite observar que a fração fina da cinza constitui aproximadamente $80 \%$ do material. A classificação da cinza de caldeira a coque devido a sua granulometria, segundo NARDI (1975), se enquadrou no grupo das cinzas volantes, onde praticamente $100 \%$ do material são constituídos por partículas menores que 0,15 mm.

0 valor de densidade real dos grãos da cinza de caldeira a coque encontrado foi de 2,06 $\mathrm{g} / \mathrm{cm} 3$, valor que aproxima de outros autores que também trabalharam a cinza, como pode ser visto na TAB. 3. Quanto aos limites de Atterberg, o material foi considerado não plástico.

Tabela 3: Valores de densidade real dos grãos de cinzas volantes dispostos na literatura.

\begin{tabular}{|c|c|}
\hline Autores & Densidade $\left(\mathrm{g} / \mathrm{cm}^{3}\right)$ \\
\hline MENDONÇA (2004) & 2,092 \\
\hline UBALDO (2005) & 2,090 \\
\hline CEZAR (2011) & 1,880 \\
\hline LOPES (2011) & 2,105 \\
\hline
\end{tabular}


O conhecimento das características químicas e mineralógicas do material natural e estabilizado é fundamental para a compreensão do comportamento dos solos durante o processo de estabilização, portanto procedeu com a realização de MEV e EDS. As imagens obtidas pelo ensaio MEV são apresentadas na FIG. 4 e a composição química da cinza, analisada por EDS é apresentada na TAB. 4.

Conforme as imagens apresentadas, foi possível observar que a cinza possui pequena granulometria e estrutura porosa e esponjosa, o que induz seu uso como material fino em camadas de pavimentos. As partículas esponjosas puderam ser facilmente observadas na da FIG. 5 e suas características quanto à absorção de água também foram notadas no decorrer dos ensaios.

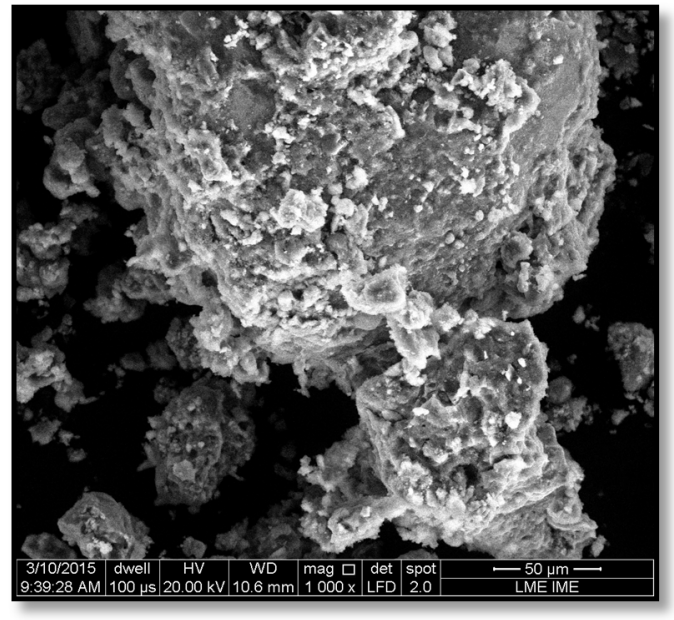

(a)

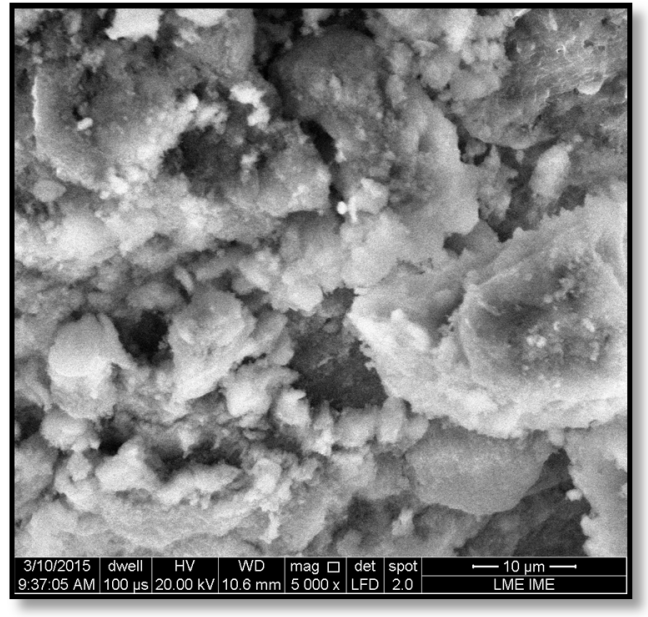

(b)

Figura 5. Imagem da amostra de cinza de caldeira a coque obtida pelo ensaio de MEV com aumento de 1000x (a), $5000 x(b)$.

Tabela 4: Composição química da cinza volante por meio do EDS.

\begin{tabular}{|c|c|c|c|c|c|}
\hline \multicolumn{2}{|c|}{ AMOSTRA 01} & \multicolumn{2}{|c|}{ AMOSTRA 02} & \multicolumn{2}{|c|}{ AMOSTRA 03} \\
\hline Composição & Porcentagem & Composição & Porcentagem & Composição & Porcentagem \\
\hline $\mathrm{MgO}$ & 2,86 & $\mathrm{MgO}$ & 3,11 & $\mathrm{MgO}$ & 0,60 \\
\hline $\mathrm{Al}_{2} \mathrm{O}_{3}$ & 3,84 & $\mathrm{Al}_{2} \mathrm{O}_{3}$ & 1,89 & $\mathrm{Al}_{2} \mathrm{O}_{3}$ & 3,92 \\
\hline $\mathrm{SiO}_{2}$ & 9,38 & $\mathrm{SiO}_{2}$ & 3,60 & $\mathrm{SiO}_{2}$ & 1,82 \\
\hline $\mathrm{SO}_{3}$ & 16,27 & $\mathrm{SO}_{3}$ & 17,60 & $\mathrm{SO}_{3}$ & 12,77 \\
\hline $\mathrm{K}_{2} \mathrm{O}$ & 0,24 & $\mathrm{~K}_{2} \mathrm{O}$ & 0,40 & $\mathrm{~K}_{2} \mathrm{O}$ & 0,47 \\
\hline $\mathrm{CaO}$ & 56,65 & $\mathrm{CaO}$ & 71,12 & $\mathrm{CaO}$ & 79,63 \\
\hline $\mathrm{V}$ & 6,84 & V & 0,49 & V & 0,48 \\
\hline $\mathrm{FeO}$ & 2,12 & $\mathrm{FeO}$ & 1,58 & $\mathrm{FeO}$ & 0,31 \\
\hline $\mathrm{NiO}$ & 1,80 & $\mathrm{NiO}$ & - & $\mathrm{NiO}$ & - \\
\hline $\mathrm{Cu}$ & - & $\mathrm{Cu}$ & 0,21 & $\mathrm{Cu}$ & - \\
\hline
\end{tabular}

É possível notar que os principais componentes da cinza, tal como listados na Tabela 3, foram $\mathrm{SO}_{3}$ e $\mathrm{CaO}$, com porcentagens médias de 15,54\% e 69,13\%. Segundo ROHDE et. al. (2006), os elementos responsáveis pela atividade pozolânica nas cinzas volantes são: $\mathrm{SiO}_{2}, \mathrm{Al}_{2} \mathrm{O}_{3}, \mathrm{Fe}_{2} \mathrm{O}_{3}$, $\mathrm{CaO}, \mathrm{MgO}, \mathrm{SO}_{3}, \mathrm{Na}_{2} \mathrm{O}$ e $\mathrm{K}_{2} \mathrm{O}$. Ainda, segundo NARDI (1975), o óxido de cálcio (CaO) geralmente produz melhores resistências no solo estabilizado.

Quanto aos ensaios de lixiviação e solubilização, a cinza de caldeira a coque foi classificado como Resíduo Não Perigoso, Classe II A - Inerte. 
Contudo, pode-se concluir que a cinza de caldeira a coque apresenta em sua composição, elementos responsáveis pelas reações pozolanicas e possui características físicas e químicas similares às cinzas volantes encontradas na literatura.

\subsection{Ensaios Mecânicos}

A partir dos ensaios de módulo de resiliência, realizados conforme DNER-ME 134/2010, podese ter duas análises distintas, porém complementares, estas que serão tratadas separadamente: Influência do tempo de cura e Influência dos teores de cinza e cal.

Para análise dos resultados de módulo de resiliência em relação ao tempo de cura adotou-se como valor de referência para cada ensaio realizado a média aritmética entre os 18 valores obtidos no ensaio, correspondentes aos pares de tensões aplicadas. DELGADO (2012) citou que, embora este procedimento não seja o mais adequado na análise dos resultados, na definição dos valores de módulo de resiliência em projetos de pavimentos, é comum se adotar esta prática, pois facilita a comparação entre os valores. São apresentados os valores médios de MR pelos tempos de cura analisados através dos gráficos mostrados nas FIG. 6 e FIG. 7.

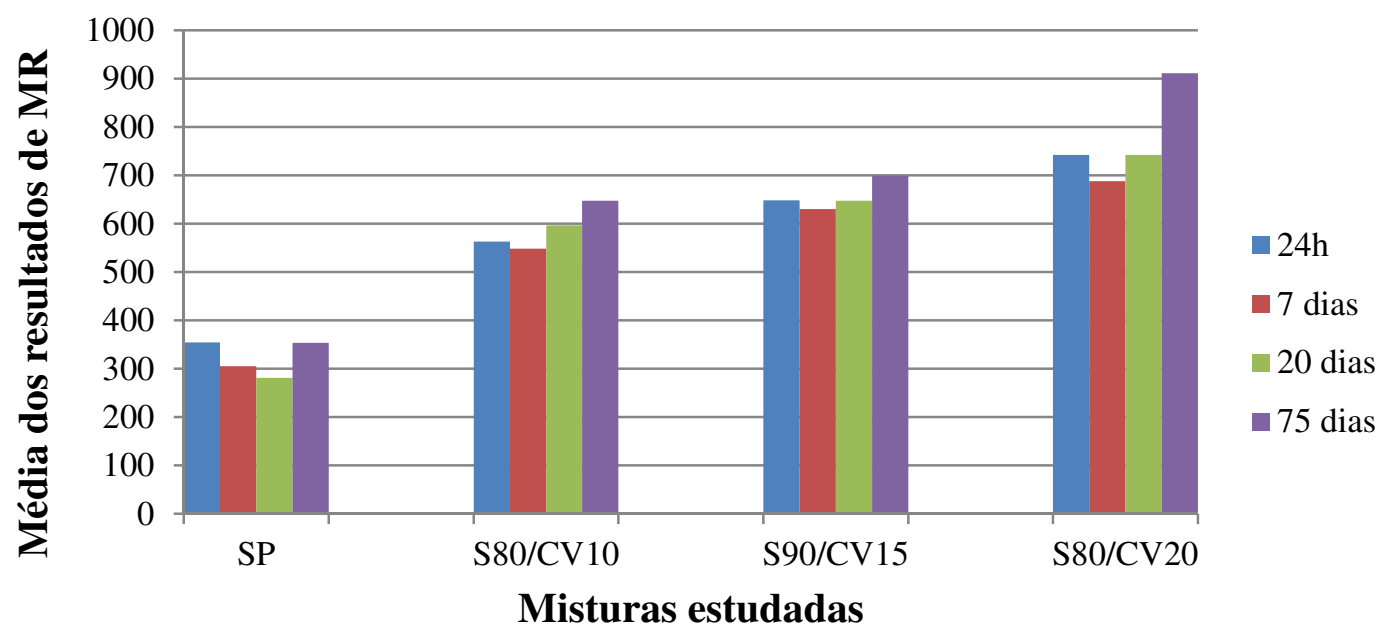

Figura 6: Variação dos valores médios de MR do solo puro e das misturas solo-cinza vs. Tempo de cura

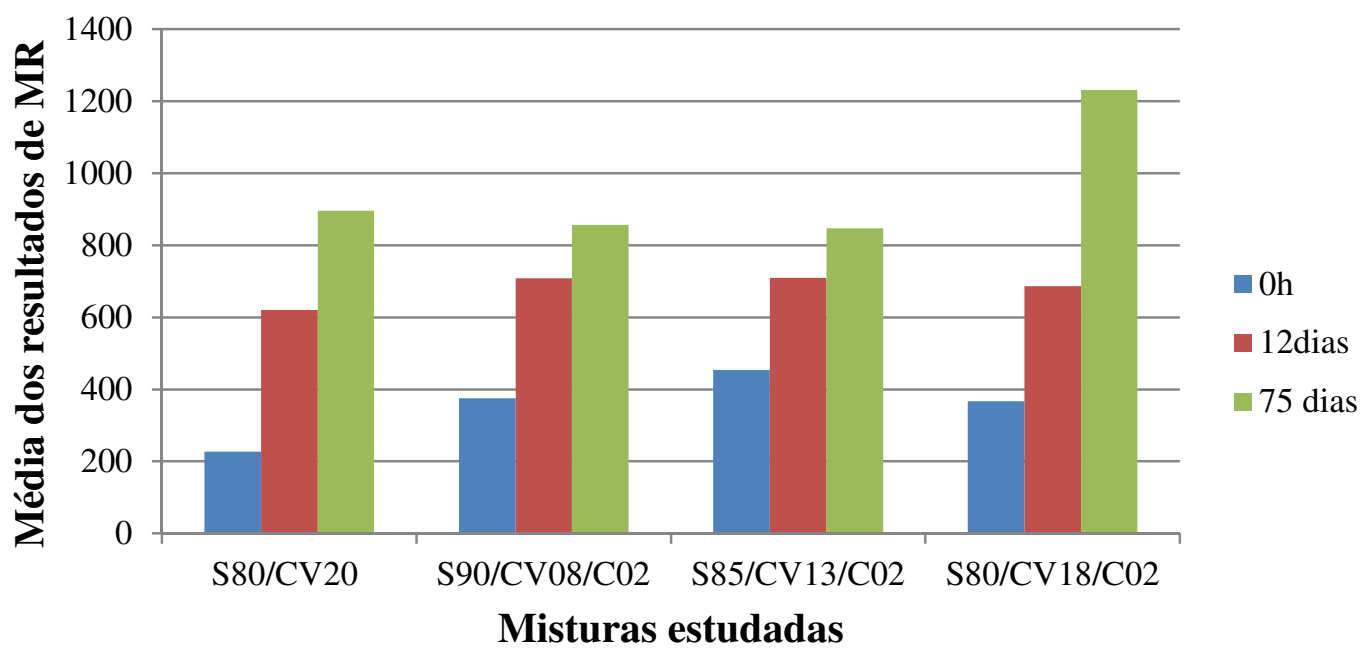

Figura 7: Variação dos valores médios de MR das misturas solo-cinza-cal vs. Tempo de cura 
Analisando primeiramente as misturas solo-cinza (ver FIG. 6), constata-se um acréscimo dos valores médios de resultados de MR entre o menor e o maior tempo de cura. No entanto, o gráfico mostra também uma pequena queda nos mesmos valores durante os primeiros 7 dias de cura, tanto nas misturas como também no solo puro. Esta queda no valor de MR da mistura é muito pequena, sendo inferior à margem de erro do ensaio associada à sua repetibilidade (usualmente até $10 \%)$. Neste caso portanto, não se verifica efeito significativo no MR dos CPs ensaiados em função do tempo de cura.

Na FIG. 7, é possível perceber também que a adição da cal, mesmo em pequenas quantidades, promoveu ganhos substanciais na resistência do material, visto que em 75 dias de cura a mistura S80/CV18/C02 (Misturas contendo 80\% de solo, 18\% de cinza e 2\% de cal) atingiu valores médios na ordem de $1200 \mathrm{MPa}$, enquanto a mistura solo-cinza correspondente, S80/CV20 (80\% de solo e $20 \%$ de cinza) onde não houve substituição da massa seca das cinzas pela cal, alcançou valores médios na ordem de $900 \mathrm{MPa}$.

Analisando agora a influência do teor dos agentes pozolânicos na mistura, sabe-se que as misturas solo-cinza e solo-cinza-cal foram ensaiadas em tempos de cura diferentes, sendo a primeira ensaiada nos tempos de cura de 24 h, 7 dias, 20 dias e 75 dias, enquanto as demais foram ensaiadas no tempo de cura de 0 h, 12 dias e 75 dias. Logo, justifica-se a apresentação dos resultados ser feita de forma dividida.

Assim sendo, as FIG.8 e FIG.9 apresentam a variação dos resultados de Módulo resiliente para cada mistura solo-cinza e solo puro ensaiada em função da tensão desviadora aplicada em um mesmo tempo de cura e as FIG. 10 e FIG. 11 apresentam variação dos resultados de Módulo resiliente para cada mistura solo-cinza-cal e solo puro também ensaiada em função da tensão desviadora aplicada em um mesmo tempo de cura.

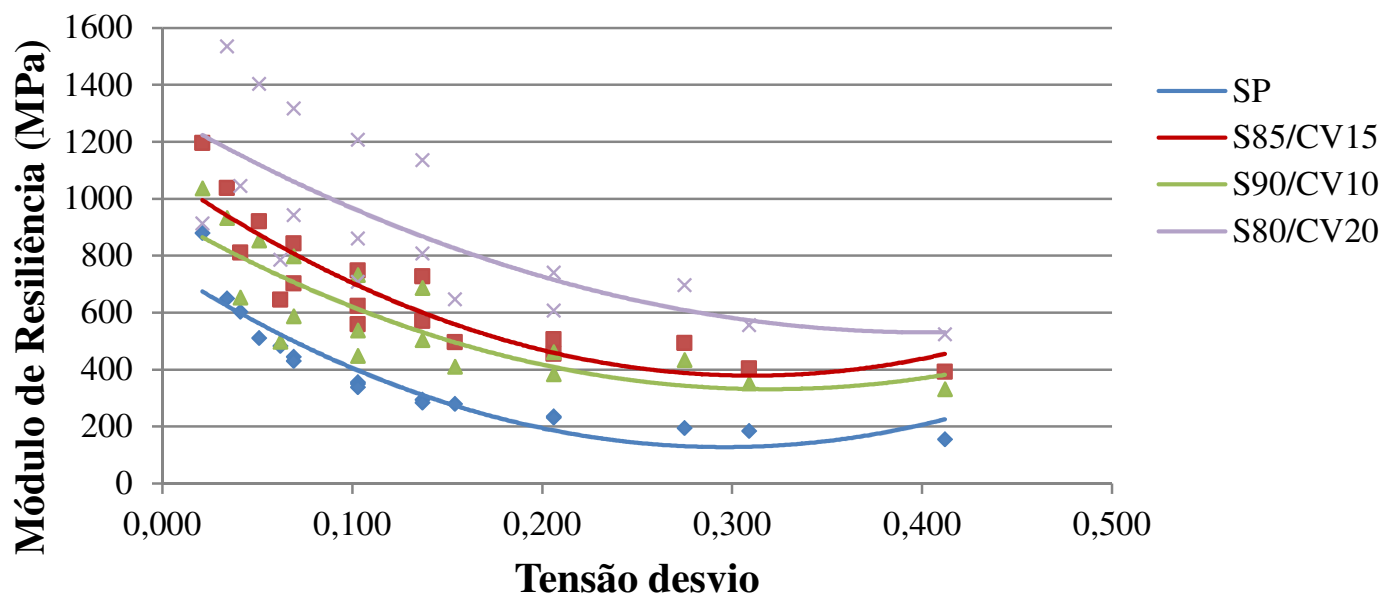

Figura 8: Variação do Módulo Resiliente vs. Tensão desviadora para as Misturas solo-cinza e para o solo puro com 24 horas de cura

Os gráficos apresentados mostraram que, desde 24 horas de cura, os CP's sofreram influência da ação das cinzas. Através da FIG.8 é possível constatar que o ganho de resistência mecânica foi imediato, podendo ser observado no ensaio realizado 24 horas após a compactação. Os gráficos deixam claro que, desde o primeiro ensaio, as misturas contendo maior teor cinza apresentaram comportamento mecânico superior, respondendo melhora à aplicação das tensões. 


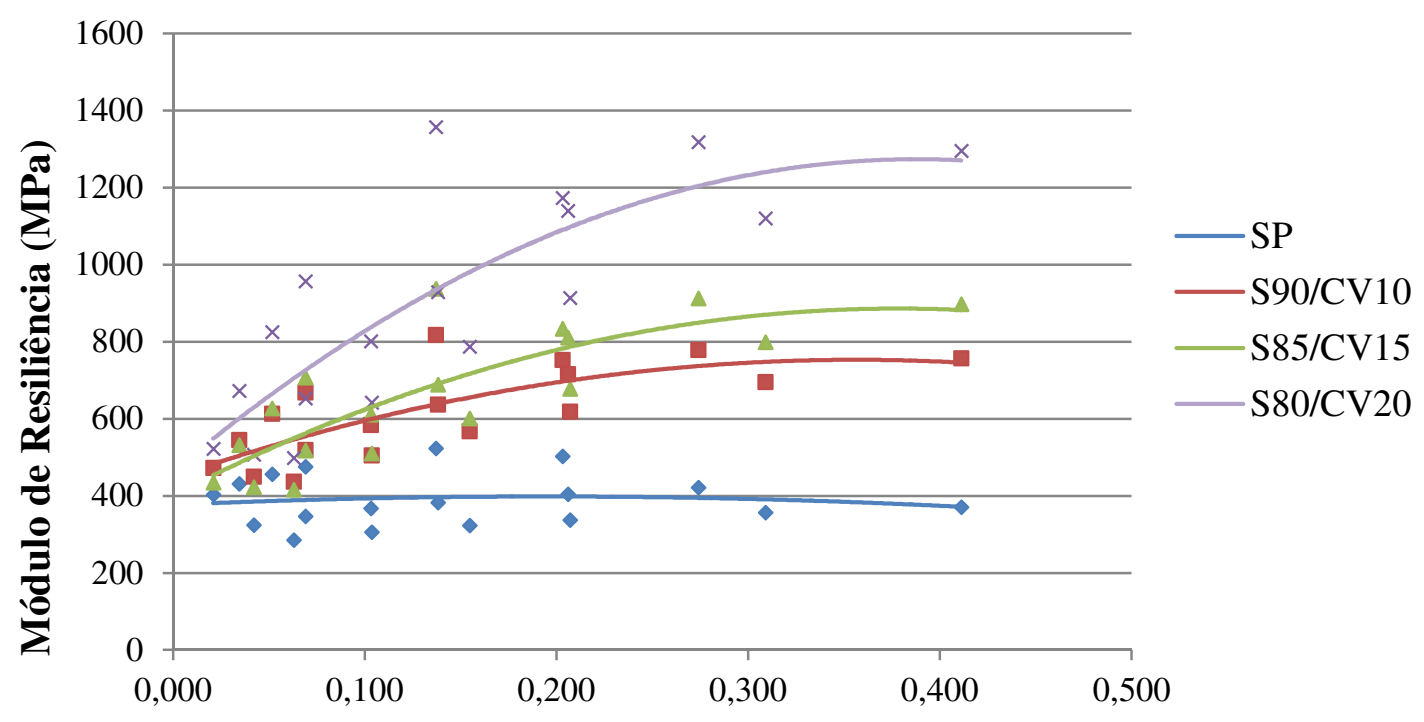

Tensão Desviadora

Figura 9: Variação do Módulo Resiliente vs. Tensão desviadora para as Misturas solo-cinza e para o solo puro com 75 dias de cura

Observa-se também o mesmo comportamento das misturas analisadas com o decorrer do tempo de cura (FIG. 9). Em 75 dias de cura, no entanto, diferentemente do ensaio com 24 horas de cura, os valores de MR passam a crescer com o aumento da tensão desviadora e a supremacia das respostas às tensões em misturas contendo maior teor de cinzas passam a ser mais evidentes em relação ao solo puro.

Partindo para as misturas solo-cinza-cal, e analisando da mesma forma que as misturas solocinza, apresentam-se as FIG. 10 e FIG.11.

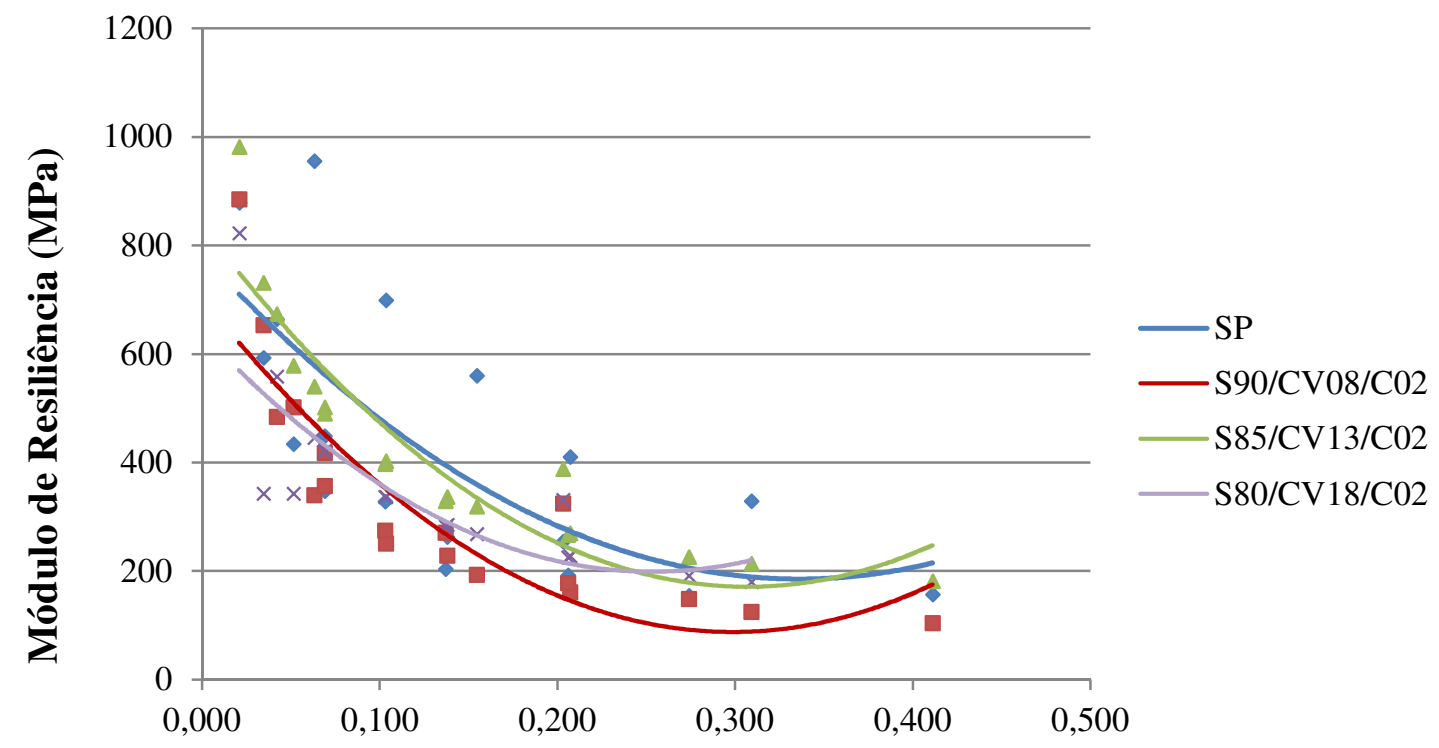

Tensão Desvio

Figura 10: Variação do Módulo Resiliente vs. Tensão desvio para as Misturas solo-cinza-cal e para o solo puro com Oh de cura 
Sabe-se que as misturas solo-cinza-cal, foram ensaiadas imediatamente após sua compactação, diferentemente das misturas solo-cinza e solo puro, que passaram por 24 horas em câmara úmida para serem submetidas ao primeiro ensaio.

Esse procedimento adotado repercutiu nos primeiros ensaios e pode ser facilmente notado na FIG.10, desta figura, nota-se que as misturas comparadas ao solo puro têm comportamentos bem semelhantes, mostrando que não houve nenhuma espécie de reação pozolânica e provando que inicialmente a adição das cinzas e da cal ocasiona melhora somente na trabalhabilidade das misturas e não influenciam seu comportamento mecânico.

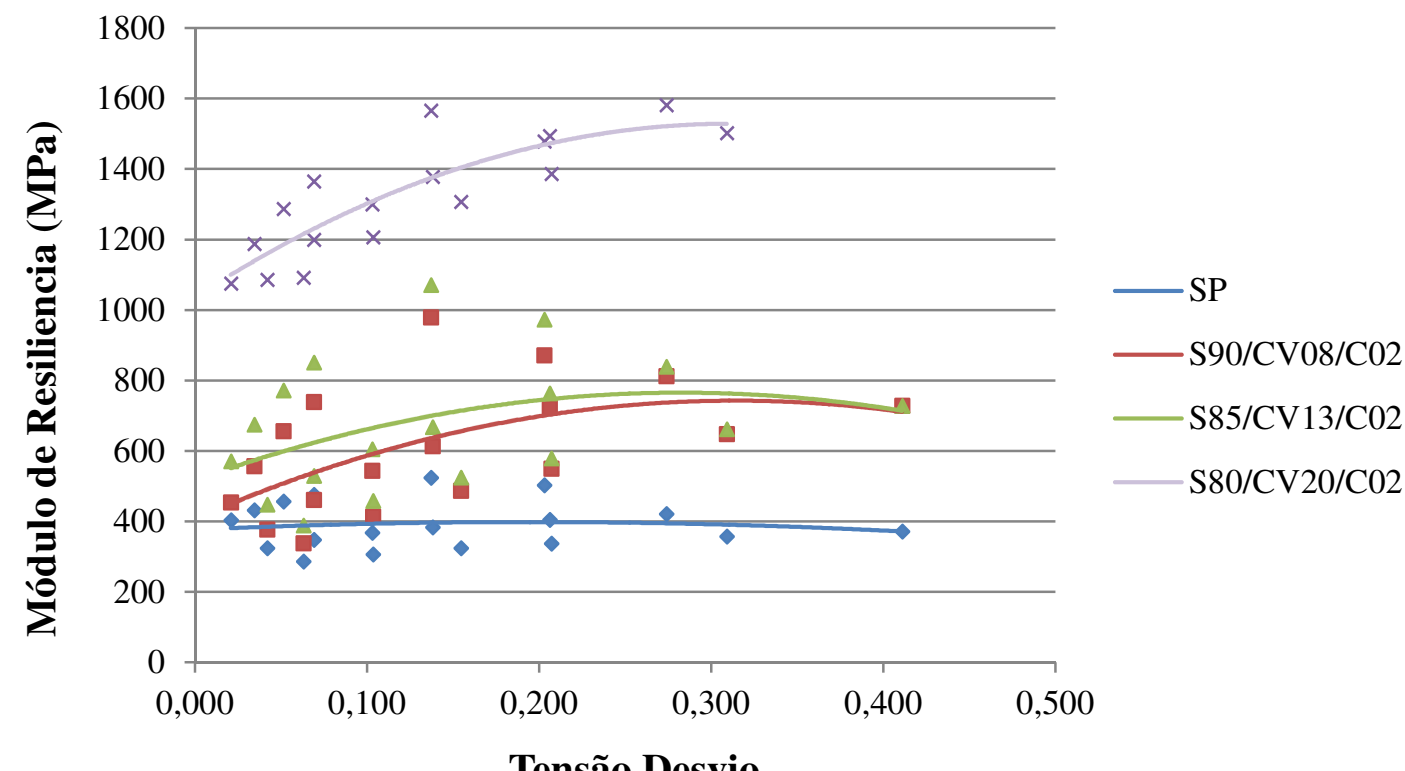

Figura 11: Variação do Módulo Resiliente vs. Tensão desvio para as Misturas solo-cinza-cal e para o solo puro com 75 dias de cura

Por sua vez, aos 75 dias, é notória a influência do tempo de cura nas misturas. Assim como nas misturas solo-cinza aos 75 dias de cura, os valores de MR passam a crescer com o aumento da tensão desviadora e o comportamento mecânico é superior à medida que se acrescenta o teor de cinza, atestado pelas melhores respostas aos diversos níveis de tensões.

\section{CONCLUSÕES}

De forma geral, concluiu-se que a adição da cinza de caldeira a coque ao solo, como agente estabilizador, proporciona melhoria tanto no quesito de comportamento mecânico para o solo, quanto para o meio ambiente, onde centenas de toneladas deixam de ocupar os pátios de resíduos e passam a ter uma finalidade nobre na Engenharia de Pavimentos.

A cinza de caldeira a coque possui características físicas e químicas similares às cinzas volantes descritas na literatura.

A análise do comportamento mecânico verificou que houve melhora no comportamento mecânico de todas as misturas contendo cinzas e este aumento foi proporcional ao teor das mesmas, corroborando com a afirmativa de ocorrência de reações pozolânicas devido à ação da cinza de caldeira a coque. Lembrando que a ação da cal como agente potencializador das reações pozolânicas também foi de fundamental importância, conduzindo a um elevado ganho de resistência das misturas. 
Portanto, pôde-se concluir, que a cinza de caldeira a coque pode ser utilizada em camadas de base de pavimentos com ou sem o uso de cal, dependendo da região onde vai ser aplicada.

\section{REFERÊNCIAS}

Associação Brasileira de Normas Técnicas. NBR 10005: Lixiviação de Resíduos - Procedimento. Rio de Janeiro, 2004. Associação Brasileira de Normas Técnicas. NBR 10006: Solubilização de Resíduos - Procedimento. Rio de Janeiro, 2004. Associação Brasileira de Normas Técnicas. NBR 12653: Materiais pozolânicos - Requisitos. Rio de Janeiro, 2014.

ASTM Standard C618, 2003, Standard Specification for Coal Fly Ash and Raw or Calcined Natural Pozzolan for Use in Concrete. ASTM International, West Conshohocken, PA, 2003, DOI: 10.1520/C0618-12A.

Ahmaruzzaman, M. A review on the utilization of fly ash. In: Progress in Energy and Combustion Science, v. 36. p.327-363, Junho de 2010, India. DOI:10.1016/j.pecs.2009.11.003.

Cezar, D. S. Características de durabilidade de concretos com cinza volante e cinza de casca de arroz com e sem beneficiamento. Dissertação (Mestrado em Engenharia Civil). Universidade Federal de Santa Maria - UFSM. Santa Maria, 2011.

Departamento Nacional de Estradas de Rodagem. DNER-ME 082/94: Solos - Determinação do limite de plasticidade. Rio de Janeiro, 1994.

Departamento Nacional de Estradas de Rodagem. DNER-ME 083/98: Solos - Análise Granulométrica. Rio de Janeiro, 1998.

Departamento Nacional de Estradas de Rodagem. DNER-ME 84/95: Agregado miúdo - Determinação da Densidade Real. Rio de Janeiro, 1995.

Departamento Nacional de Estradas de Rodagem. DNER-ME 122/94: Solos - Determinação do limite de liquidez. Rio de Janeiro, 1994.

Departamento Nacional de Estradas de Rodagem. DNER-ME 256/94: Solos compactados com equipamento miniatura - Determinação da perda de massa por imersão. Rio de Janeiro, 1994.

Departamento Nacional de Estradas de Rodagem. DNER-ME 258/94: Solos compactados em equipamentos miniatura - MiniMCV. Rio de Janeiro, 1994.

Departamento Nacional de Infraestrutura de Transporte. DNIT 181/2018: Módulo de Resiliência. Rio de Janeiro, 2018. Rio de Janeiro, 2018.

Farias, E. R. A utilização de Misturas Solos/Cinza Pesada na Pavimentação - Análise de Aspectos de Comportamento Mecânico e Ambiental. Dissertação (Mestrado em Engenharia Civil) - Universidade Federal de Santa Catarina, Florianópolis, 2005.

Hoover, J.M., Huffman, R.T., Davidson, D.T. Soil Stabilization Field. In: 41st Annual meeting of the highway research board, Washington DC, EUA, 1962.

Hester, J.A. Fly ash in roadway construction, fly ash utilization. In: proceedings of Edison electric institute, National coal association and bureau of mines symposium, pp 87-90., 1967.

Lav, A. H.; Lav, M. A.; Goktepe, A. B. Analysis and design of a stabilized fly ash as pavement base material. In: Fuel - Special Issue: The 2005 World of Coal Ash Conference, Novembro de 2006, Istanbul. v. 85, Issue 16, p. 2249-2370. DOI:10.1016/j.fuel.2006.05.017.

Leandro, R.P. Estudo laboratorial acerca da possibilidade de aproveitamento da cinza pesada de termelétrica em base e sub-base de pavimentos flexíveis. Dissertação (Mestrado em Engenharia Civil) - Escola de Engenharia de São Carlos, Universidade de São Paulo, São Carlos, 2005.

Leandro, R. P.; FABBRI, G. T. P. Aproveitamento da cinza pesada de carvão mineral da construção de bases e sub-bases de pavimentos flexíveis. In: Panorama Nacional da Pesquisa em Transportes. v. 1. p. 1-12. Vitória- ES, 2009

Lopes, L. S. E. Análise do comportamento mecânico e ambiental de misturas solo-cinzas de carvão mineral para camadas de base de pavimentos. Dissertação (Mestrado em Engenharia Civil). Pontifícia Universidade Católica - PUC-Rio. Rio de Janeiro, 2011.

Malmann, J. E. C. Estabilização pozolânica de cinzas volantes e pesada com cal dolomítica hidratada e areia, curadas pelos processos de autoclavagem e câmara à temperatura constante. Dissertação (Mestrado em Engenharia Civil) - Universidade Federal do Rio Grande do Sul, Porto Alegre, 1996.

Marcon, A. F. Durabilidade e módulo de elasticidade de misturas areia-calcinza volante. Dissertação (Mestrado em Engenharia Civil) - Universidade Federal do Rio de Janeiro, Rio de Janeiro, 1977.

Margon, P. V. Influência do uso das cinzas de carvão mineral de termelétricas em argamassas de revestimento: dosagem por curvas granulométricas. Dissertação (Mestrado em Engenharia Civil). Universidade Federal de Santa Catarina - UFSC, 2002.

Nardi, J.V. Estabilização de areia com cal e cinza volante; efeito do cimento como aditivo e de brita na mistura. Dissertação (Mestrado em Engenharia Civil) - Universidade Federal do Rio de Janeiro, Rio de Janeiro, 1975

Netto, R. M. Materiais Pozolânicos. Monografia (Engenharia Civil) Escola de Engenharia da Universidade Federal de Minas Gerais - UFMG, Belo Horizonte, 2006.

Nogami, J.S. e Villibor D.F. Pavimentação de baixo custo com solos lateríticos. Editora Villibor: São Paulo/SP, 1995. 213p.

Pinto, S. Estabilização de areia com cal e cinza volante. Dissertação (Mestrado em Engenharia Civil) - Universidade Federal do Rio de Janeiro, Rio de Janeiro, 1971.

Rhode, G. M.; Zwonok, O.; Chies, F.; Silva, N. I. W. Cinzas de carvão fóssil no Brasil - Aspectos técnicos e ambientais. vol.1 Porto Alegre: CIENTEC, 2006. 
Sazzad, Bin-Shafique. TUNCER, B. E., CRAIG, H. B., AYKUT, S. Incorporating a fly-ash stabilised layer into pavement design. In: Geotechnical Engineering, n.157, Issue GE4, p. 239-249. London, October 2004.

DOI: 10.1680/geng.2004.157.4.239.

Silveira, V. L. Estabilização de solos com cinza de caldeira a coque para camadas de pavimentos. Dissertação (Mestrado em Engenharia de Transportes) - Instituto Militar de Engenharia, Rio de Janeiro, 2015.

Silva, M. V. Desenvolvimento de tijolos com a incorporação de cinzas de carvão e lodo provenientes de estação de tratamento de água. Dissertação (Mestrado em Ciência na área de tecnologia nuclear - Materiais). Autarquia associada à Universidade de São Paulo. São Paulo, 2011.

Siqueira, J. S. Reciclagem de resíduo a partir de cinzas de carvão mineral: Produção de argamassas. Dissertação (Engenharia Química). Universidade Federal do Pará - UFPA. Belém, 2011.

Sundstron, M. G. Caracterização e avaliação das cinzas da combustão de carvão mineral geradas na região do baixo Jacuí- RS. Dissertação (Mestrado em Avaliação de impactos ambientais em mineração). Centro Universitário La Salle - UNILASALLE. Canoas, 2012.

Ubaldo, M.O. Uso de cinzas de carvão da composição de uma cobertura de rejeitos de mineração. Dissertação (Mestrado em Engenharia Civil) - Universidade Federal do Rio de Janeiro, Rio de Janeiro, 2005.

Vizcarra, G.O.C. Aplicabilidade de cinzas de resíduos sólidos urbanos em camadas de bases de pavimentos. Dissertação (Mestrado em Engenharia Civil) - Pontifícia Universidade Católica. Rio de Janeiro, 2010. 